\title{
Effect of Liquid Phase Additions on Microstructure and Thermal Properties in Copper and Copper-Diamond Composites
}

\author{
A. Rape, ${ }^{1}$ X. Liu, ${ }^{2}$ A. Kulkarni, ${ }^{3}$ and J. Singh ${ }^{1}$ \\ ${ }^{1}$ Applied Research Laboratory, The Pennsylvania State University, University Park, PA 168022, USA \\ ${ }^{2}$ Momentive Performance Materials, 22557 Lunn Road, Strongsville, OH 44149, USA \\ ${ }^{3}$ Department of Mechanical Engineering, The Pennsylvania State University, University Park, PA 16802, USA
}

Correspondence should be addressed to A. Rape; amr340@psu.edu

Received 28 September 2014; Accepted 15 November 2014; Published 3 December 2014

Academic Editor: Bin Li

Copyright (C) 2014 A. Rape et al. This is an open access article distributed under the Creative Commons Attribution License, which permits unrestricted use, distribution, and reproduction in any medium, provided the original work is properly cited.

\begin{abstract}
This study details a new approach to creating copper-diamond composite materials for thermal management applications by using a two-phase (solid-liquid) approach in powder metallurgy using Field Assisted Sintering Technology (FAST). Silver-copper alloyed powder at eutectic compositions was used as a nonreactive liquid phase while $\mathrm{Cu}_{5} \mathrm{Si}$ was used as a reactive liquid phase. Microstructure results are reported favorably comparing the additions of a small amount of liquid phase to pure solid state sintering. Additionally, EDX results indicate that the liquid phase material fills gaps at the interface of the matrix and diamond particle resulting in improved microstructure and density. Thermal conductivity results show that liquid phase additions improve the thermal conductivity of composites compared to composites without any liquid phase, but $\mathrm{Si}$ additions cause a severe drop in baseline conductivity.
\end{abstract}

\section{Introduction}

Thermal management is a critical issue in the development of high performance microelectronics such as computers, cell phones, and other electronics. Heat sink plates are used to dissipate the heat generated by the integrated circuit (IC). Two major properties are used to determine performance of heat sink plates-thermal conductivity and coefficient of thermal expansion (CTE). It is desirable to have as high thermal conductivity as possible to move heat away from the source and a CTE to match the CTE of the source (which is generally silicon) to prevent damages that can occur from a CTE mismatch. The problem is that one of these properties comes at the expense of the other in most traditional materials. Materials such as copper and aluminum with very high thermal conductivities tend to have a very high CTE value and vice versa. Materials such as diamond, carbon nanotubes (CNT), and pyrolytic carbon have excellent thermal conductivities coupled with low CTE values. However, diamonds are very expensive and often not feasible as a heat sink plate, and graphite/CNT lack mechanical rigidity.
A basic approach to overcoming these challenges is to create a composite material using a highly conductive metal (such as copper) as the matrix material and incorporate a highly conductive form of carbon to further enhance the thermal conductivity while lowering the CTE [1]. However, copper has zero wettability with carbon. This leads to porosity along the grain boundary when combining the materials into a composite. The presence of porosity leads to a poor interface between the matrix and diamond which is associated with a significant decrease in thermal conductivities, which reduces the effectiveness of diamond additions [2]. Improvements to the interface are possible either by changing the chemistry of the matrix through the addition of an alloying element that will chemically react with diamond (or CNT) or possibly by liquid phase sintering [3].

Limited research has been conducted in the area of encapsulating diamond by liquid phase sintering in an aluminum matrix [4] by using Al-eutectic alloys (such as Al-Mg, Al$\mathrm{Si})$. Any addition of impurities in Al matrix often results in reported reduction of its thermal conductivity. The loss of thermal conductivity was compensated by the large volume 


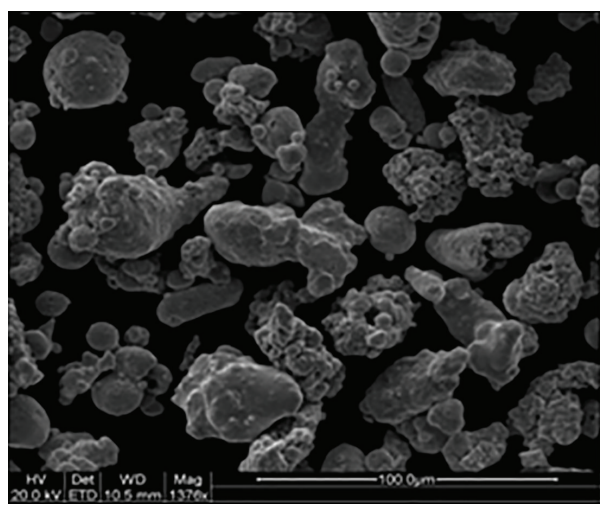

(a)

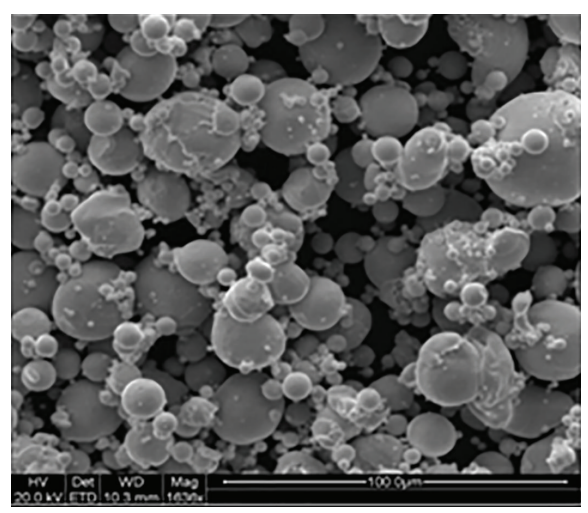

(b)

Figure 1: SEM images of the starting powders (a) Cu powder (b) $72 \mathrm{wt} . \% \mathrm{Ag}-28 \mathrm{wt} . \% \mathrm{Cu}$ powder.

fraction of diamond addition before seeing its benefit, that means require large volume fraction of diamond addition in the Al matrix. A similar approach was used by the same group using an aluminum-silicon eutectic composition as the liquid phase material in the silver matrix. An improvement in the thermal conductivity of Ag with diamond and Al-Si eutectic was reported over pure silver [5].

There were two primary objectives of this research. The first goal was to understand the behavior and impact of liquid phase additions to a solid copper powder system. The system would then be densified by FAST. A silvercopper alloy at the eutectic composition was selected as the material used to understand liquid phase behavior during FAST sintering because of its low melting temperature and elemental similarity to the copper matrix.

Diamond particles are added to the system once the sintering behavior of liquid containing systems and the optimum parameters are selected. Another liquid phase addition, copper silicide $\left(\mathrm{Cu}_{5} \mathrm{Si}\right)$, was also studied to determine if it was possible for the liquid phase to form a chemical reaction between the silicon with the diamond particles to form silicon carbide ( $\mathrm{SiC})$. The goal of the chemical reaction is to improve the interface between the matrix and diamond particle to improve the thermal properties of the materials. The resulting composite materials are studied to determine the effect of the liquid phase on the thermal conductivity of the sintered composite.

\section{Materials and Methods}

2.1. Field Assisted Sintering Technology. Field Assisted Sintering Technology (FAST) is a relatively new sintering technique that utilizes the simultaneous application of high temperature, uniaxial pressure, and high density DC current. A very high, pulsed electric current allows for an extremely fast heating rate, which is combined with the pressure, and results in the rapid densification of powders $[6,7]$. The powder to be sintered is placed inside a graphite die between two graphite punches. The punches and die are separated from the powder with graphite foil. This prevents reaction with the graphite die at the temperatures used in this study. Pressure is applied to the punches and current is passed through them, as well as the die. The current through the die provides conductive heat to the powder. Current can also flow through the powder which causes Joule heating instantly. The current flows through the powder along the contact points between the particles (which become the grain boundaries) because it is the path of least resistance. Any resistance between current paths can cause fast heating and lead to melting, vaporization, and/or plasma formation. Under pressure, the particles rearrange and deform resulting in mechanical bonding as well as solid state joining through grain boundary diffusion. When the pressure is combined with high temperatures, the sintering rate is significantly improved. This process has the advantage over other methods of having significantly shorter sintering times and lower sintering temperatures [8].

2.2. Material Preparation. Elemental copper powder (-325 mesh, 40 um, purity: 99.99\% [American Element]) is shown in Figure $1(\mathrm{a})$. Silver-Copper $(\mathrm{Ag} 72 \mathrm{Cu})$ alloyed powder at the eutectic composition of $72 \mathrm{wt} . \% \mathrm{Ag}$ and $32 \mathrm{wt} . \%$ $\mathrm{Cu}$ [Cimini and Associates] powder is shown in Figure 1(b). Copper Silicide $\left(\mathrm{Cu}_{5} \mathrm{Si}\right)$ [ESPI metals] was ground by mortar and pestle and screened through a -325 mesh sieve. Powders were weighed into cylindrical plastic containers with 5,10 , and $20 \mathrm{wt} . \%$ of the eutectic powder along with the copper powder. The powers were blended using a Resodyn acoustic mixer using a recipe of $50 \%$ intensity for 30 seconds.

Diamond particles $(40-60 \mu \mathrm{m})$ were also added into the metal blends at up to 40 volume $\%$. The blending recipe had to be modified to $100 \%$ intensity for 60 seconds for these blends due to drastic difference in particle density.

The mixed powders were placed into a $40 \mathrm{~mm}$ graphite die lined with graphite foil. The die was placed into the FAST system (FCT-HP D25, Germany) for densification. The samples that contained any of the $\mathrm{Ag} 72 \mathrm{Cu}$ were heated to $825^{\circ} \mathrm{C}$ with $45 \mathrm{MPa}$ determining the effect of sintering time on the liquid phase in the matrix. The $\mathrm{Cu}_{5} \mathrm{Si}$ containing samples was heated to $900^{\circ} \mathrm{C}$ with $45 \mathrm{MPa}$ of applied pressure. The temperature was measured by an optical pyrometer reading the graphite die $1 \mathrm{~mm}$ from the sample surface. Table 1 summarizes the starting powder compositions that were used 
TABLE 1: Summary of starting powers and processing conditions.

\begin{tabular}{|c|c|c|c|}
\hline $\begin{array}{l}\text { Starting powder } \\
\text { (10 vol\% diamond is assumed) }\end{array}$ & Sintering temperature $\left({ }^{\circ} \mathrm{C}\right)$ & Heating rate $\left({ }^{\circ} \mathrm{C} \mathrm{min}^{-1}\right)$ & Sintering time (min) \\
\hline Pure copper & 825 & 50 & 20 \\
\hline \multirow{3}{*}{$\mathrm{Ag} 72 \mathrm{Cu}$} & 725 & \multirow{3}{*}{50} & 20 \\
\hline & 760 & & 20 \\
\hline & 825 & & Squeezed out \\
\hline \multirow{4}{*}{$\begin{array}{l}\text { Copper }+10 \text { wt. } \% \text { Ag72Cu } \\
\text { (with and without diamond) }\end{array}$} & \multirow{4}{*}{825} & 10 & $\mathrm{n} / \mathrm{a}$ \\
\hline & & \multirow{2}{*}{100} & 5 \\
\hline & & & 20 \\
\hline & & 400 & $\mathrm{n} / \mathrm{a}$ \\
\hline Copper + 20 wt. $\%$ Ag72Cu & 825 & 100 & 20 \\
\hline Copper + 10 wt. $\% \mathrm{Cu}_{5} \mathrm{Si}+\mathrm{Dia}$ & 900 & 50 & 20 \\
\hline
\end{tabular}

and processing conditions each sample experienced in the study.

Sintered sample densities were determined using Archimedes' method. $\mathrm{Cu}$ and eutectic samples were then cut with an alumina cut-off wheel. The samples containing diamond were cut by wire EDM. The samples were polished with diamond suspensions to $1 \mu \mathrm{m}$ and polished to $0.04 \mu \mathrm{m}$ with a silica solution. Microstructural information was collected using both optical and scanning electron microscopes (Jeol 6700). Energy dispersive X-ray spectroscopy was used to determine concentration differences within the grain structure of sintered samples.

\section{Results and Discussion}

3.1. Material Development and Characterization of Materials Containing $\mathrm{Ag} 72 \mathrm{Cu}$. The $\mathrm{Ag} 72 \mathrm{Cu}$ powder was sintered to understand its melting behavior when being subjected to FAST processing. The power was sintered to $99.8 \%$ theoretical density at $725^{\circ} \mathrm{C}$ with an applied load of $45 \mathrm{MPa}$ for 15 minutes with a $50^{\circ} \mathrm{C} \mathrm{min}^{-1}$ heating rate. Figure 2 shows the microstructure of the sintered eutectic powder. Characteristic microstructure of melting was observed in the sintered sample showing that there was localized melting of the eutectic powder well below the theoretical melting point of the material $\left(780^{\circ} \mathrm{C}\right)$.

The $\mathrm{Ag} 72 \mathrm{Cu}$ powder was then heated to various temperatures to determine its melting behavior in the FAST system. It was shown that the material underwent a phase transformation from solid to liquid at $780^{\circ} \mathrm{C}$, which is the eutectic melting temperature for the material. This is evidenced by the rapid change in piston displacement as measured by the FAST unit. The piston's velocity changed rapidly as a result of the material melting and displacing itself from the die. Figure 3 shows two different FAST experiments under otherwise identical conditions heated to $760^{\circ} \mathrm{C}$ and $825^{\circ} \mathrm{C}$. It is clear from lack of change in piston displacement that no bulk melting occurred at $760^{\circ} \mathrm{C}$ while the entire amount of material melted at $780^{\circ} \mathrm{C}$. The melting was further evidenced by the fact that material squeezed out of die/punch combination and beaded up around the punch. SEM images of that beaded material are shown in Figures 2(c) and 2(d).

The Ag72Cu powder was blended with copper and heated to $825^{\circ} \mathrm{C}$ and $45 \mathrm{MPa}$ with different heating rates and holding times to develop an understanding of the behavior of the liquid in the system. This temperature was chosen to ensure the eutectic powder would be above its established melting temperature of $780^{\circ} \mathrm{C}$. The amount of eutectic powder added was varied to determine the optimal amount that could be used in coordination with an addition of a highly conductive additive. Figure 4 shows SEM images of 10 and $20 \mathrm{wt} . \%$ eutectic powder additions to the copper powder. The material squeezed out of the die assembly when 20 wt.\% of $\mathrm{Ag} 72 \mathrm{Cu}$ was blended with the balance of copper powder. It is thought that this amount of liquid in the system left the structurally weak. Smaller amounts of $\mathrm{Ag} 72 \mathrm{Cu}(\leq 10 \mathrm{wt} . \%)$ allow copper matrix to form a skeleton-like structure for which the liquid Ag72Cu can flow and fill porosity. The "squeezing out" effect can be observed by the general lacking of eutectic phase in $20 \mathrm{wt} . \%$ eutectic sintered samples. This can be explained by the scenario that when more eutectic powder is added a larger percentage of the total system becomes liquid. The result of this is that there is less solid structure to add rigidity to the system. The liquid metal is able to escape when external pressure is applied to the system.

The heating rate was varied from $20^{\circ} \mathrm{C} \mathrm{min}^{-1}$ to $400^{\circ} \mathrm{C} \mathrm{min}^{-1}$ to determine the effect on sintering and liquid behavior in the copper-Ag72Cu system. There is not an obvious difference in microstructure as different heating rates. However, the fact that $20 \mathrm{~min}$ hold times were used in each case may have erased any effect from the heating rates. Less Ag diffusion would be expected for the samples that experienced high heating rates but that would have been negated by long times at the maximum temperature where the diffusion could proceed.

The samples were held at their maximum temperature for 5 and 20 minutes to determine the effect of time at maximum temperature on the behavior of the liquid in the sample. The effect of the hold time is shown in Figure 5. It is clear that the shorter hold time allows more liquid to remain at the grain boundaries instead of diffusing into the copper grains. 


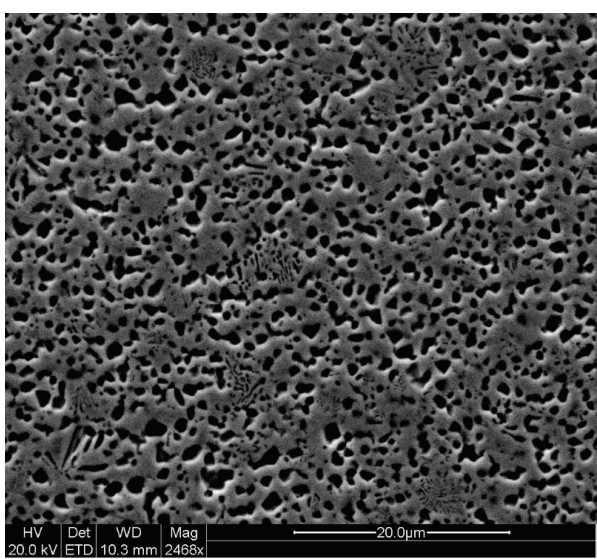

(a)

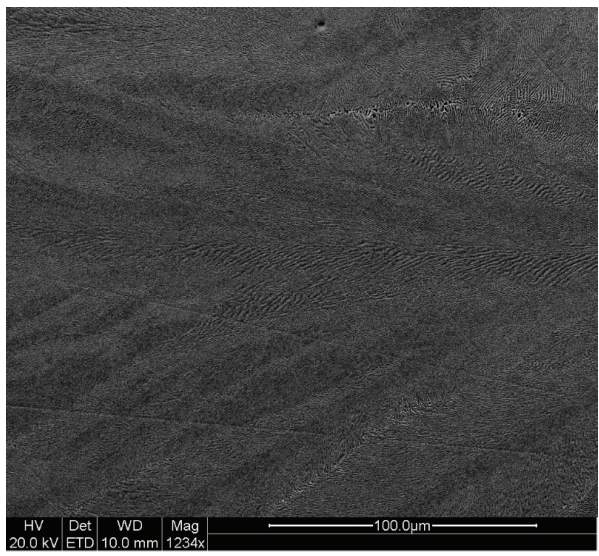

(c)

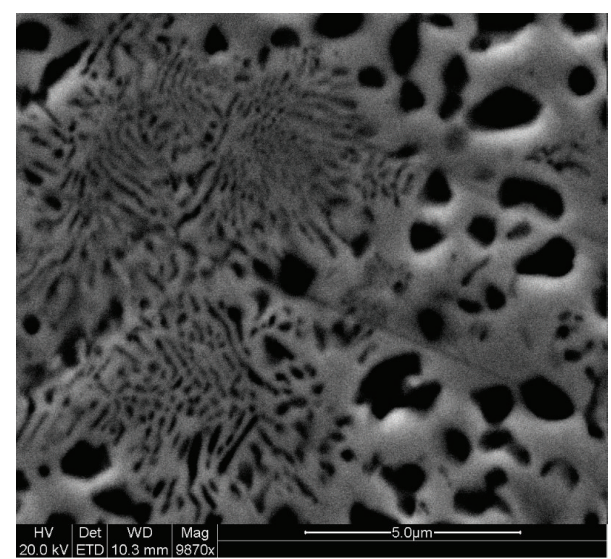

(b)

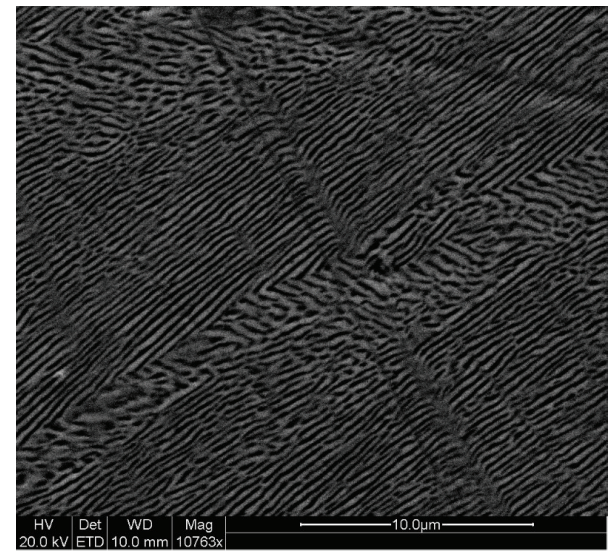

(d)

Figure 2: SEM images of sintered Ag72Cu powder at $725^{\circ} \mathrm{C}(\mathrm{a}, \mathrm{b})$. Localized melting can be clearly observed. SEM images at $1200 \mathrm{x}$ and $10000 \mathrm{x}$ of the beaded material clearly showing the material was melted and squeezed out (c, d).

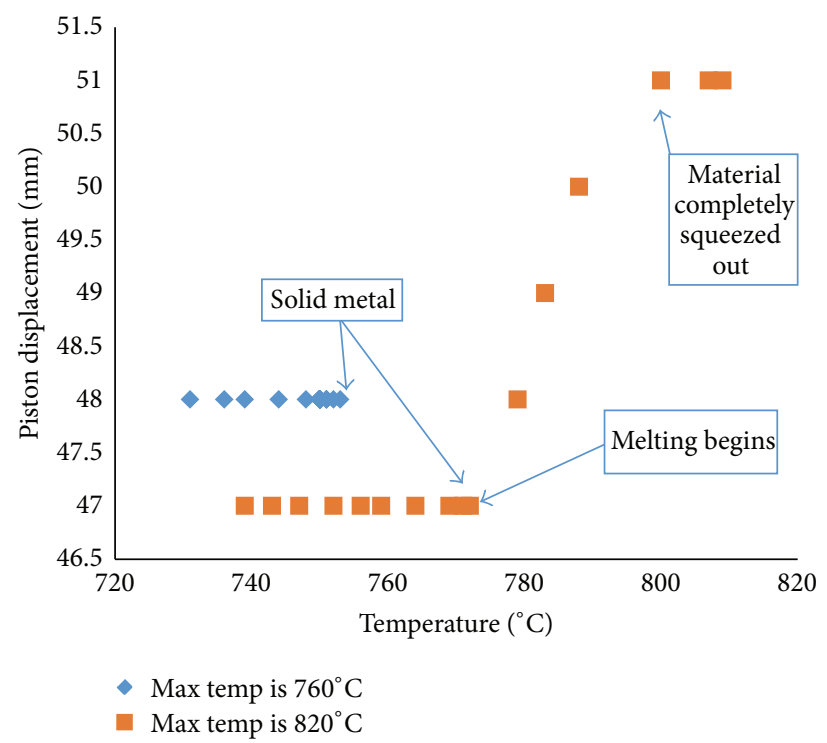

Figure 3: Graph of piston displacement of two different FAST experiments at temperatures $760^{\circ} \mathrm{C}$ and $825^{\circ} \mathrm{C}$. Both runs were conducted at $50^{\circ} \mathrm{C} \mathrm{min}^{-1}$ with a load of $45 \mathrm{MPa}$. It is evident from the plot that the material quickly changes from solid to liquid at $780^{\circ} \mathrm{C}$. 


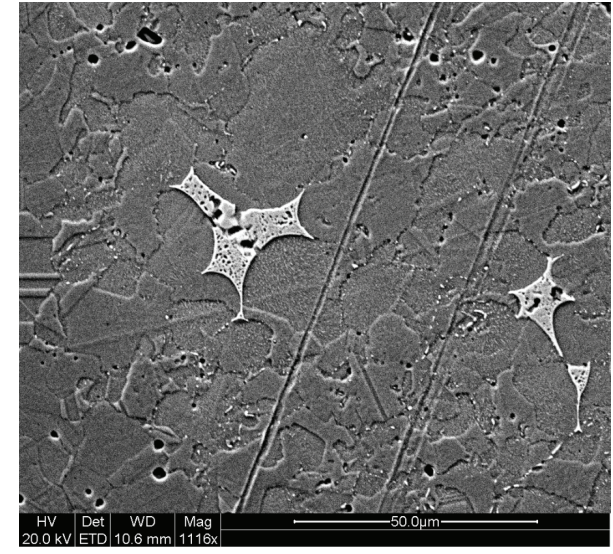

(a)

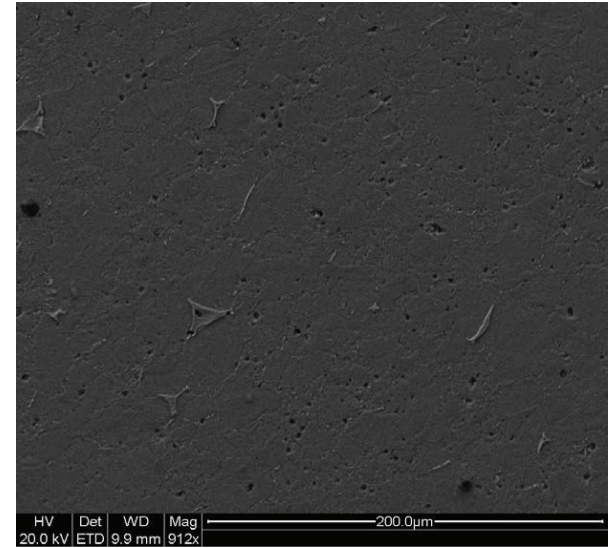

(b)

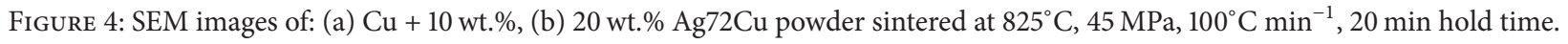
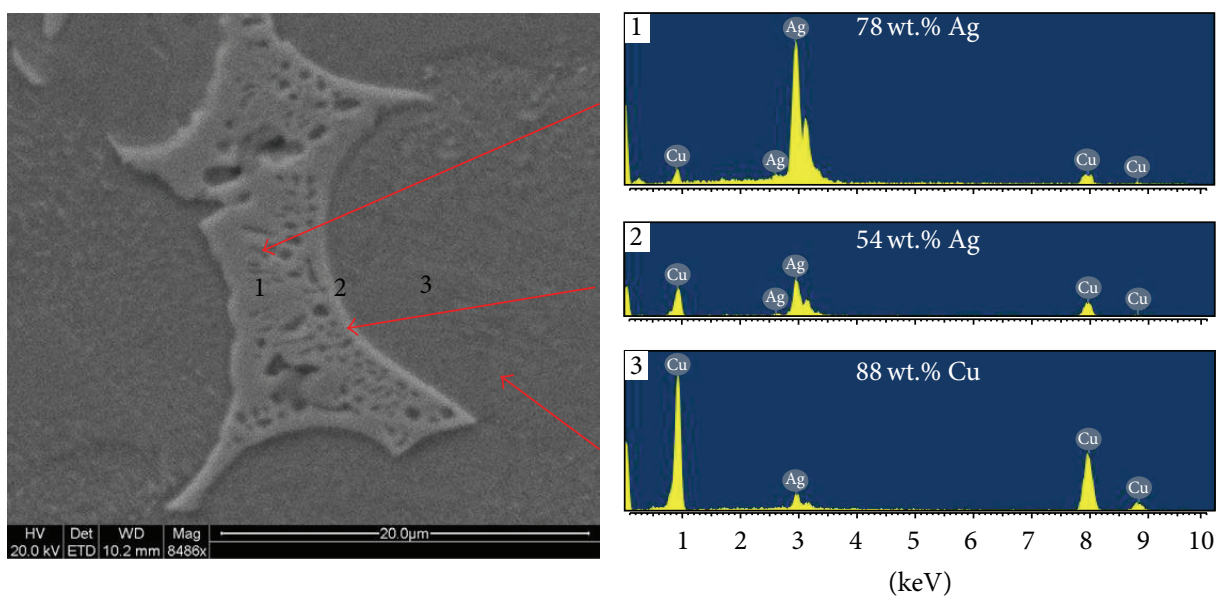

(a)
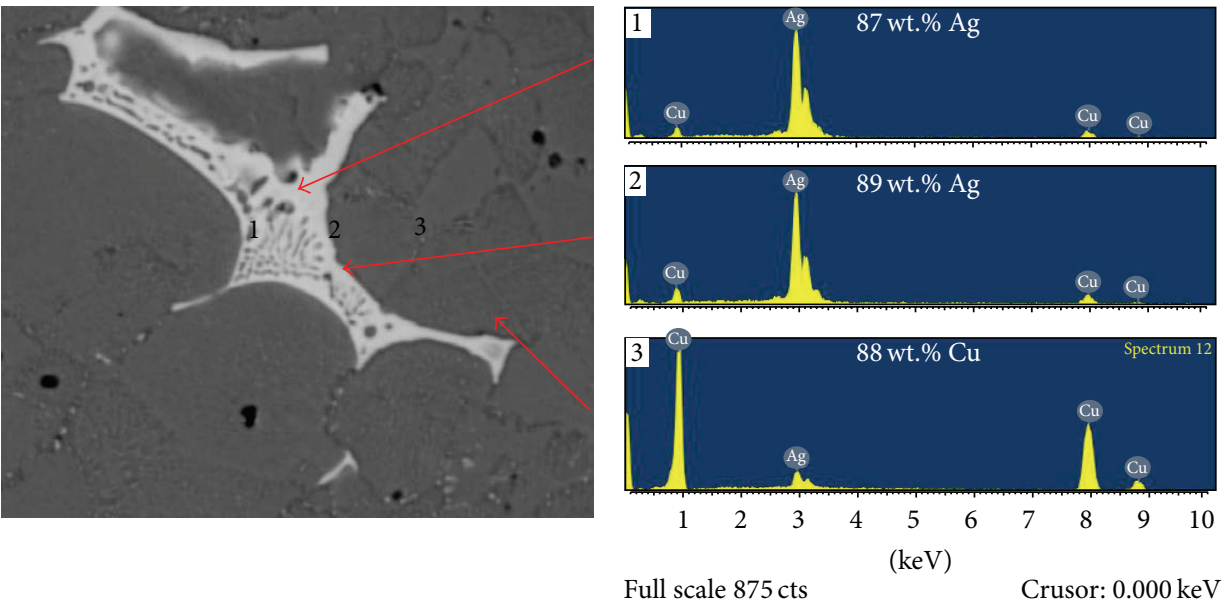

(b)

Figure 5: SEM image and EDX analysis of $\mathrm{Cu}+10 \mathrm{wt} . \%$ eutectic held at $825^{\circ} \mathrm{C}$ for sintering time of (a) 5 minutes and (b) 20 minutes. 


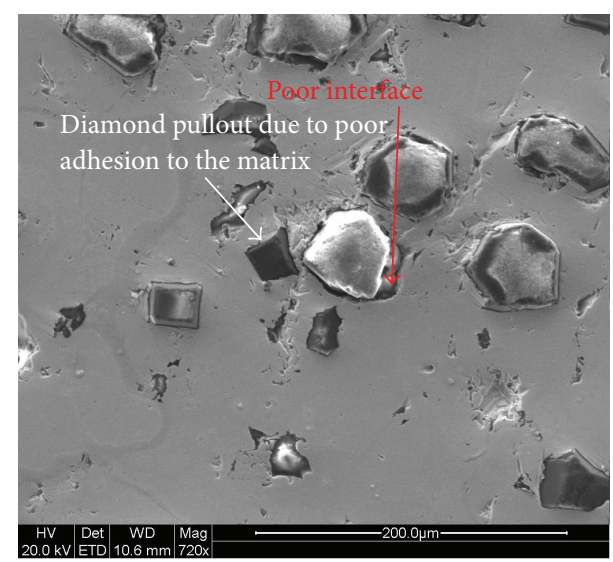

(a)

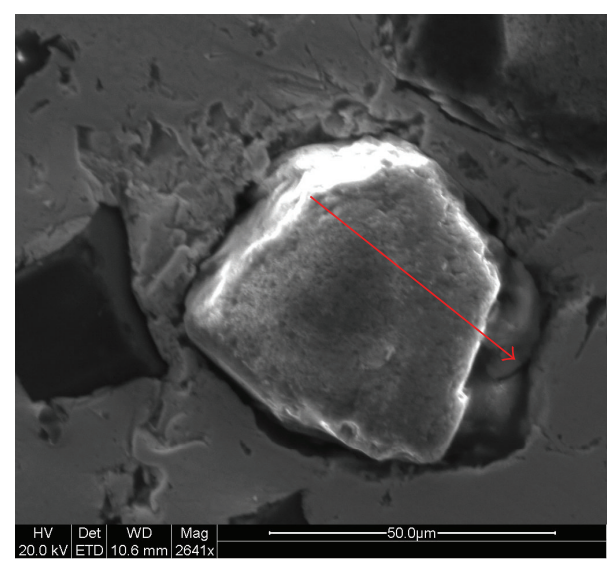

(b)

FIGURE 6: (a) Low and (b) high magnification SEM images clearly showing the poor interface that exists between the copper matrix and diamond particles.

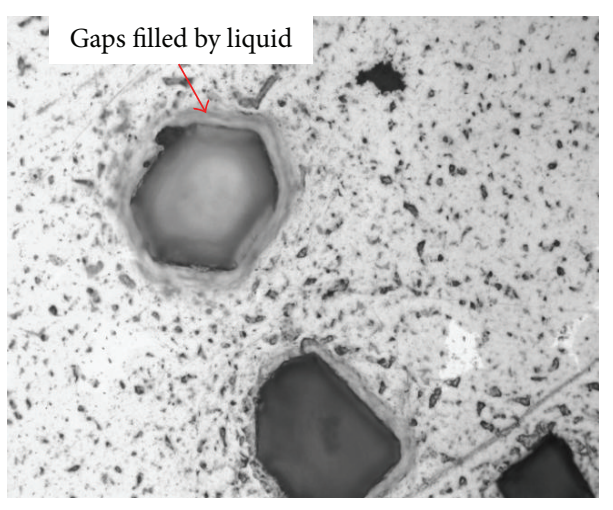

(a)

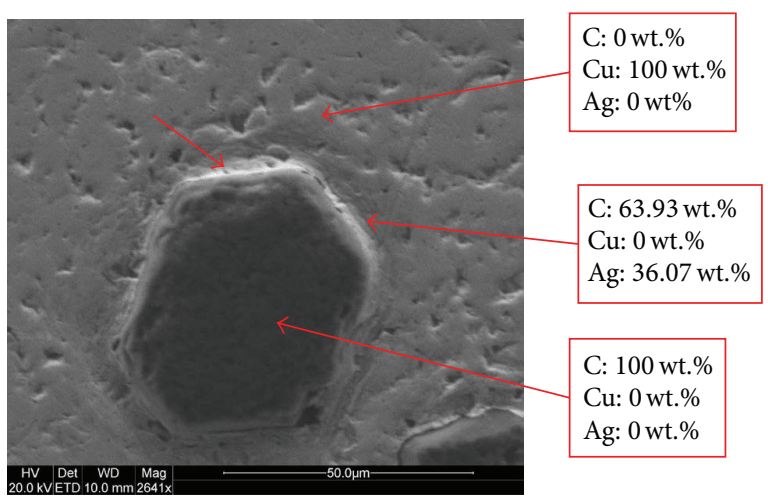

(b)

Figure 7: (a) Optical image and (b) SEM image including EDX spot analysis of Cu-10 wt.\% Ag72Cu-10 vol.\% diamond clearly showing the presence of liquid phase at the copper-diamond interface during sintering.

Holding the sample longer at maximum temperature allows for more diffusion of atoms from the liquid eutectic phase into the copper grains. As diffusion proceeds, atoms from the liquid eutectic phase migrate into the copper matrix and solidify, as they are no longer at the eutectic composition.

The diffusion behavior was probed using EDX for the Ag72Cu samples. Figure 5 shows an SEM image and EDX analysis of experiments held at the maximum temperature of $825^{\circ} \mathrm{C}$ for 5 minutes (Figure 5(a)) and 20 minutes (Figure 5(b)). The diffusion profiles show that regardless of the sintering time, copper diffuses from the liquid phase into copper matrix rapidly leaving behind a silver rich phase at the grain boundary. A small percentage of silver also diffuses into the copper matrix. There is an intermediate boundary layer in both cases of roughly equal composition. This suggests that the kinetics for copper self-diffusion is preferential to silver diffusion in copper in the FAST system under these processing conditions.

3.2. Influence of Liquid Phase on Thermal Properties. Pure copper powder was sintered with diamond particles to highlight the porosity that can form at the interface between the materials when no measures are taken to mitigate the problem. The copper and diamond SEM images are shown in Figure 6 . The poor interface is clearly visible and highlighted by arrows.

Figure 7 shows the optical and SEM microstructure of composites that were prepared using a pure copper matrix with additions of both $10 \mathrm{wt} \% \mathrm{Ag} 72 \mathrm{Cu}$ and $10 \mathrm{vol} . \%$ diamond. The improvement of the interface due to the presence of the liquid phase at the grain boundaries is evident. The liquid phase appeared to move freely along the grain boundaries and fill voids, especially at the interfaces of the copper and diamond particles.

Figure 8 shows SEM images of $\mathrm{Cu}-10$ wt.\% $\mathrm{Cu}_{5} \mathrm{Si}-10 \%$ Dia. The microstructure similarly shows much more cohesive interfaces between the matrix and diamond. The low magnification image shows signs of diamond pullout indicating the lack of chemical bonding between the diamond and silicon. The high magnification images show pockets of $\mathrm{Cu}_{5} \mathrm{Si}$ along the grain boundaries, which have negative implications on the thermal conductivity of the material. 


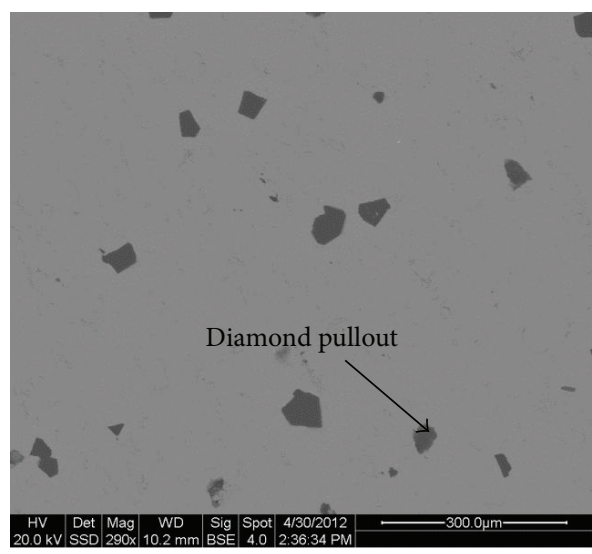

(a)

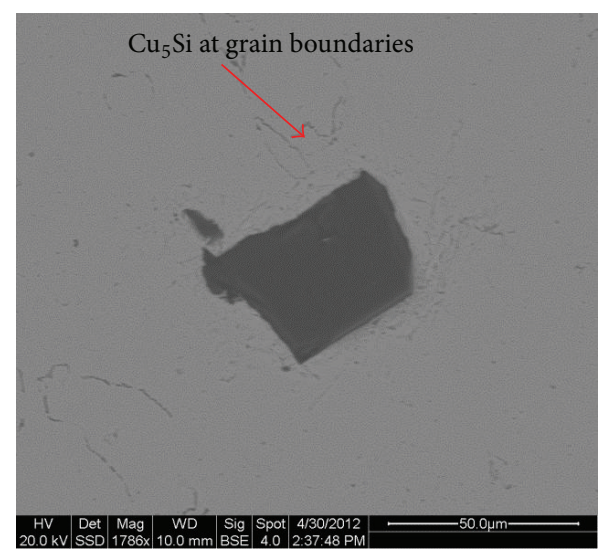

(b)

Figure 8: (a) Low and (b) high magnification SEM images of Cu-10 wt.\% $\mathrm{Cu}_{5} \mathrm{Si}-10 \%$ Dia samples.

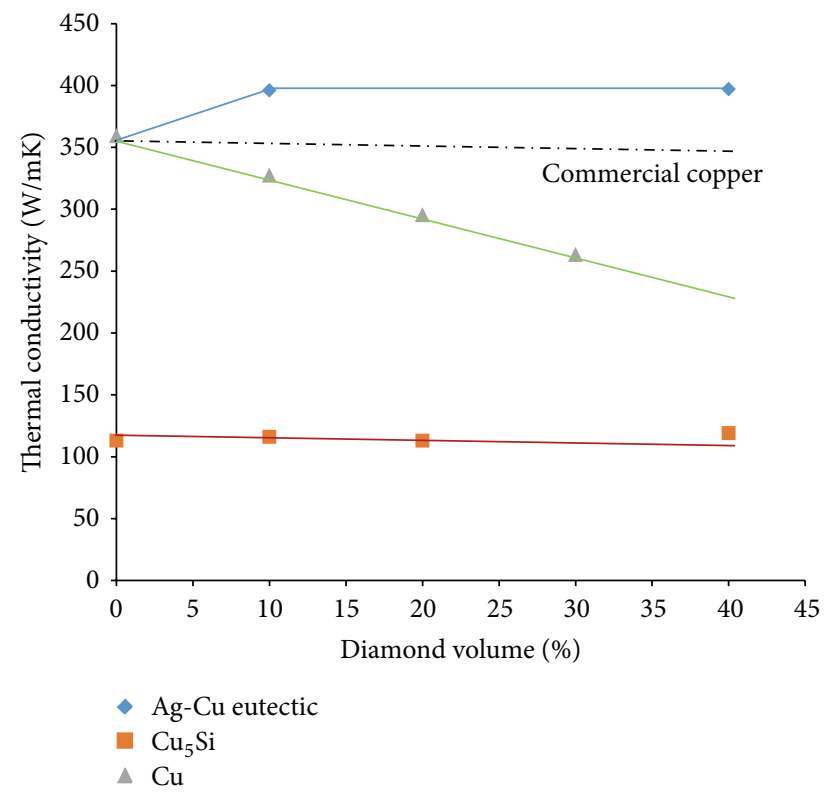

FIgure 9: Thermal conductivities of $\mathrm{Cu}, \mathrm{Cu}-\mathrm{Ag} 72 \mathrm{Cu}$, and $\mathrm{Cu}-\mathrm{Cu}_{5} \mathrm{Si}$ systems with diamond additions.

The thermal conductivity of both systems is shown in comparison with pure copper in Figure 9. The presence of liquid phase in the matrix allows the diamond particles to be encapsulated, which improves the interface over a pure copper matrix. The interface improvement leads to a noneffect of thermal conductivity as opposed to a decline which is the case for pure copper. In the case of the eutectic system, all of the components have a high thermal conductivity and so the conductivity of the baseline material is not affected. However, $\mathrm{Cu}_{5} \mathrm{Si}$ additions dramatically drop the thermal conductivity of the baseline material, by almost $75 \%$ of pure copper. This means that $\mathrm{Cu}_{5} \mathrm{Si}$ cannot be considered a suitable additive for thermal management materials. The unchanged thermal conductivity also implies that the Si did not have any form of reaction with the diamond to promote bonding at the interface. This is not completely unexpected as the reaction between $\mathrm{Si}$ and $\mathrm{C}$ for $\mathrm{SiC}$ does not have a strong propensity to occur compared to other carbide forming materials such as $\mathrm{Ti}$ and $\mathrm{Zr}$.

\section{Conclusions}

This experiment has shown that copper-silver alloyed powder of eutectic composition and copper silicide can be added to copper powder to form a two-phase, solid-liquid sintering process below the melting temperature of the copper matrix. Experiments have shown that the additional components melt in the FAST system very rapidly at the theoretical melting temperature of the material. The following conclusions can be drawn about the inclusion of liquid eutectic phase from the microstructure.

(i) The liquid phase encapsulates diamond particles very effectively and significantly improves the interface between diamond particles and the matrix.

(ii) The optimal amount of eutectic powder appeared to be $10 \%$ for the conditions examined in this study (pressure, temperature, heating rate, etc.).

(iii) EDX analysis shows that copper diffusion from the eutectic material occurs relatively rapidly into the copper matrix leaving a high silver concentration at the interface.

(iv) While $\mathrm{Cu}_{5} \mathrm{Si}$ is effective at encapsulating the diamond, it drops the baseline conductivity dramatically and cannot be considered as a thermal management material.

(v) No chemical bonding occurs between either $\mathrm{Ag} 72 \mathrm{Cu}$ or $\mathrm{Si}$ and diamond and so there is no improvement in the thermal conductivity as the volume fraction of diamond increases.

It is clear that the use of a two-phase approach to sintering can improve the interface between traditionally incompatible materials. 


\section{Conflict of Interests}

The authors declare that there is no conflict of interests regarding the publication of this paper.

\section{References}

[1] K. Yoshida and H. Morigami, "Thermal properties of diamond/copper composite material," Microelectronics Reliability, vol. 44, no. 2, pp. 303-308, 2004.

[2] T. Schubert, L. Ciupinski, W. Zielinski et al., "Interfacial characterization of $\mathrm{Cu} /$ diamond composites prepared by powder metallurgy for heat sink applications," Scripta Materials, vol. 58, pp. 263-266, 2008.

[3] T. Schubert, B. Trindade, T. Weißgärber, and B. Kieback, "Interfacial design of $\mathrm{Cu}$-based composites prepared by powder metallurgy for heat sink applications," Materials Science and Engineering A, vol. 475, no. 1-2, pp. 39-44, 2008.

[4] K. K. Mizuuchi, "Thermal conductivity of diamond particle dispersed aluminum matrix composites fabricated in solidliquid co-existent state by SPS," Composites. Part B: Engineering, vol. 42, pp. 1029-1034, 2011.

[5] K. Mizuuchi, K. Inoue, Y. Agari et al., "Processing of diamond particle dispersed aluminum matrix composites in continuous solid-liquid co-existent state by SPS and their thermal properties," Composites Part B: Engineering, vol. 42, no. 4, pp. 825-831, 2011.

[6] E. A. Olevsky, S. Kandukuri, and L. Froyen, "Consolidation enhancement in spark-plasma sintering: impact of high heating rates," Journal of Applied Physics, vol. 102, no. 11, Article ID 114913, 2007.

[7] A. Rape, S. Chanthapan, J. Singh, and A. Kulkarni, "Engineered chemistry of $\mathrm{Cu}-\mathrm{W}$ composites sintered by field-assisted sintering technology for heat sink applications," Journal of Materials Science, vol. 46, no. 1, pp. 94-100, 2011.

[8] J. R. Groza and A. Zavaliangos, "Sintering activation by external electrical field," Materials Science and Engineering A, vol. 287, no. 2, pp. 171-177, 2000. 

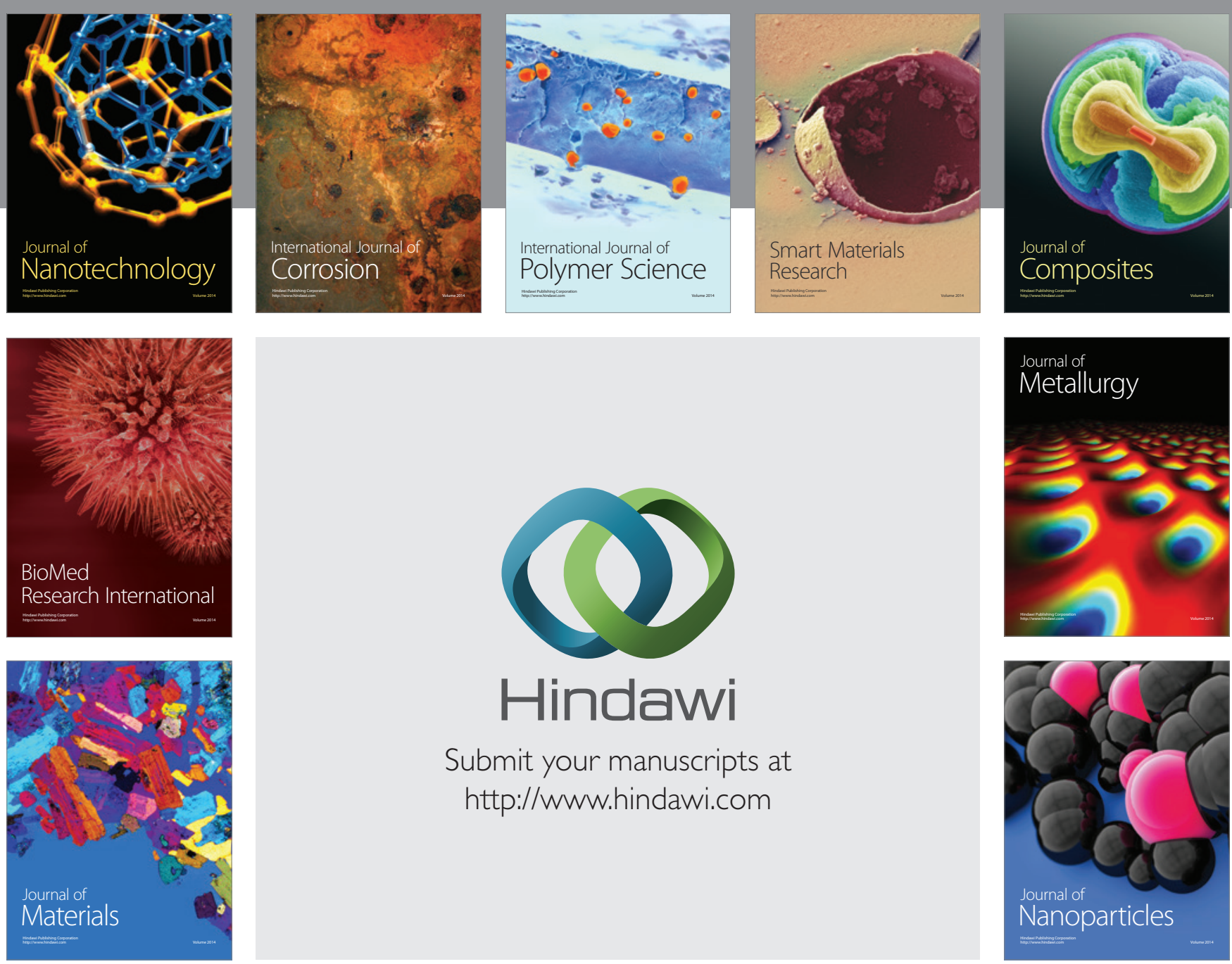

Submit your manuscripts at http://www.hindawi.com
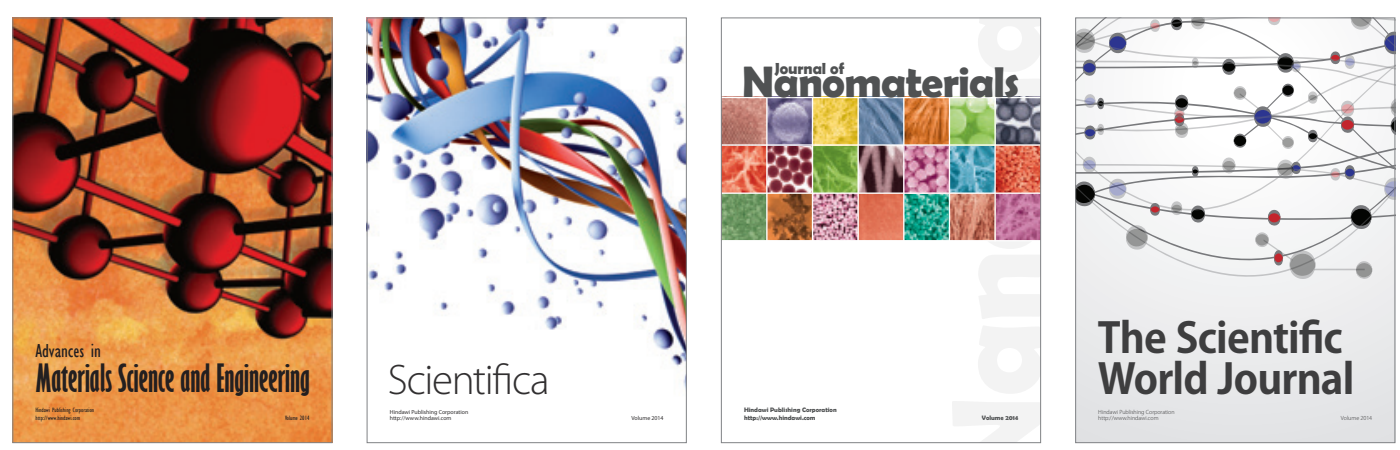

\section{The Scientific World Journal}
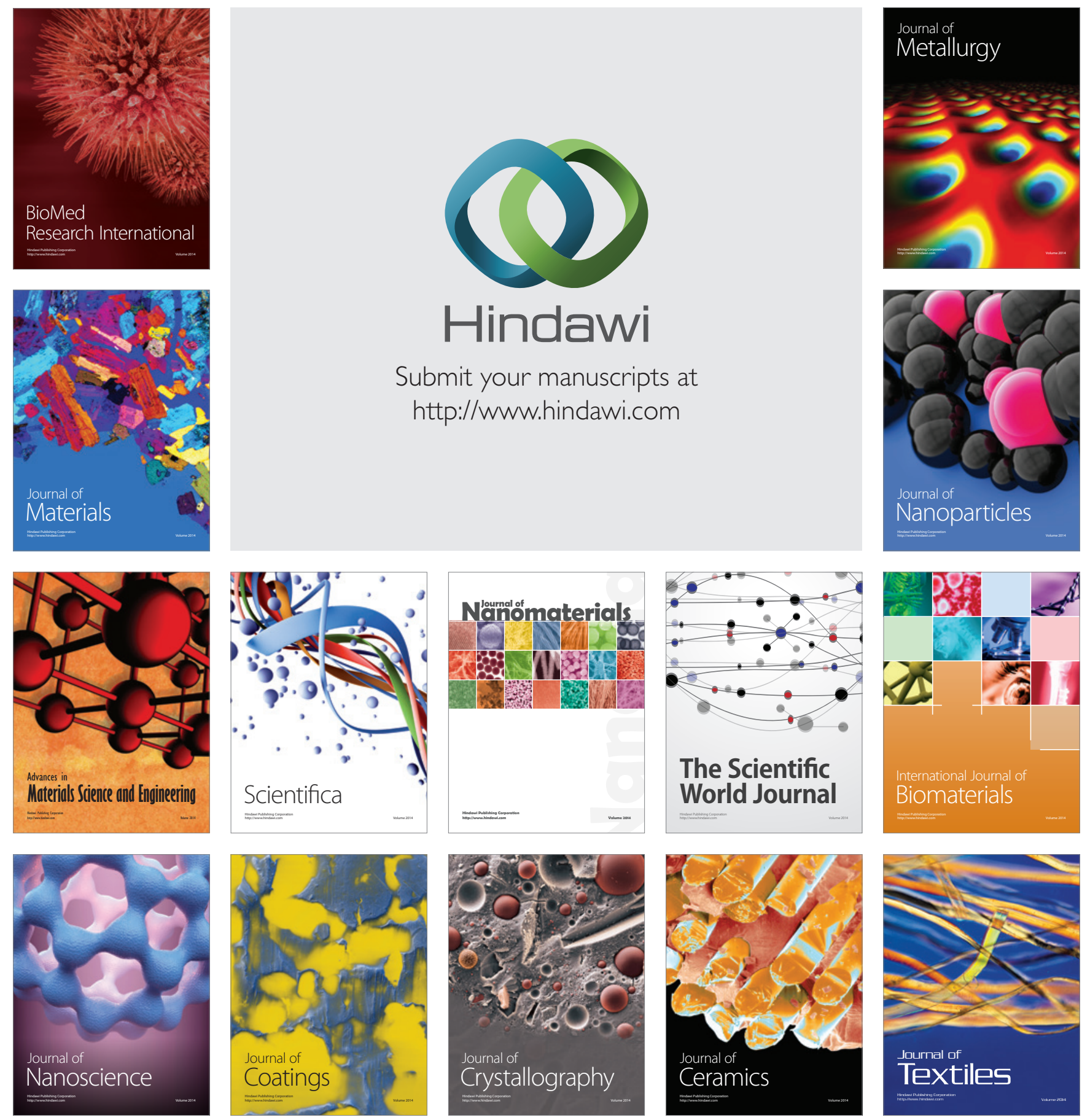